\title{
Antibiotic Apocalypse
}

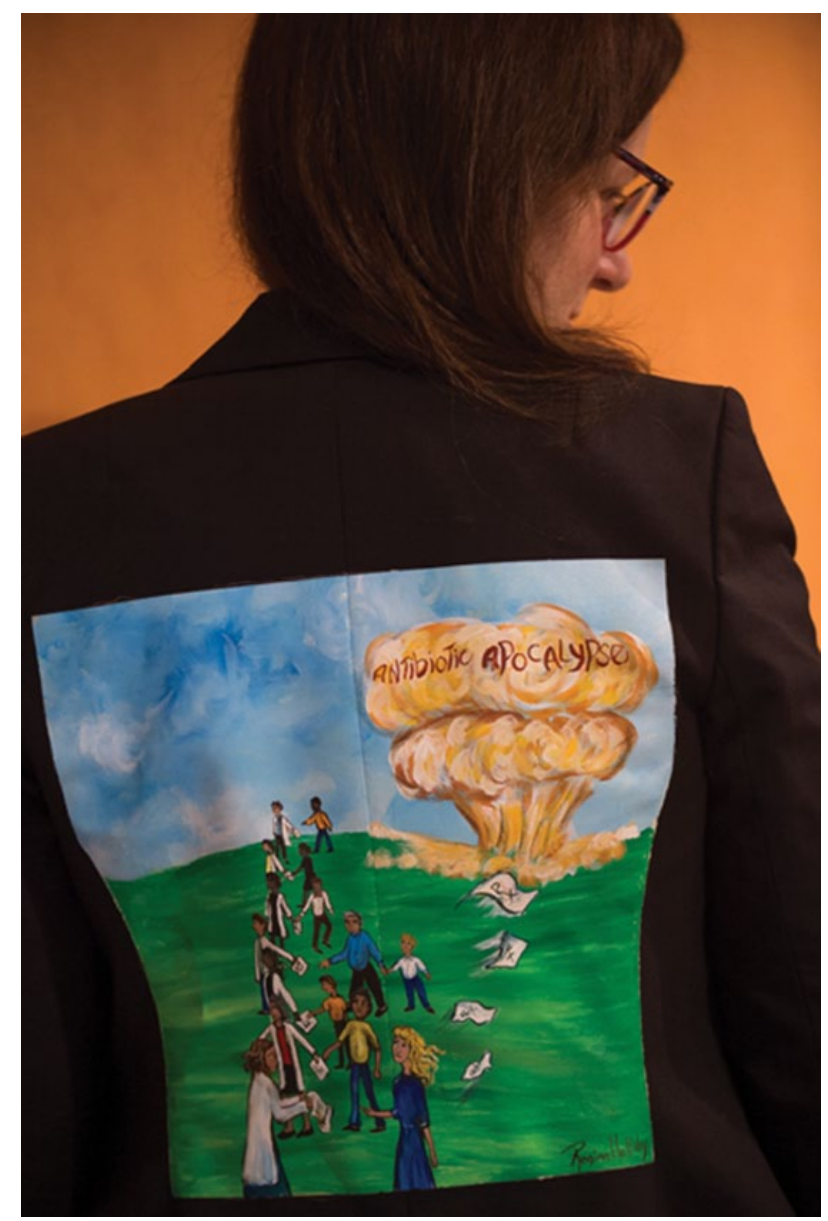

John Evely Photography

This jacket is called "Antibiotic Apocalypse." It was painted by artist Regina Holliday, a well-known US health activist who is working to create a Walking Gallery of health care stories (http://reginaholliday.blogspot.ca/2014/07/the-walkinggallery-year-iv.html). She painted it using a story I wrote for CPJ in 2013 on my experience questioning antibiotic prescriptions (146/3, p. 151). In the painting, you can see 6 of the pharmacists blindly handing out prescriptions, while only the one in the foreground engages with her patient.

-Kelly Grindrod, BScPharm, ACPR, PharmD, MSc 